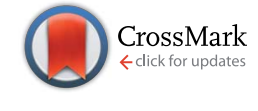

Cite this: J. Anal. At. Spectrom., 2014 29,2425

DOI: 10.1039/c4ja90057j

www.rsc.org/jaas

\section{Correction: Characterization of laser ablation sample introduction plasma plumes in fs-LA-ICP-MS}

\author{
N. L. LaHaye, S. S. Harilal, ${ }^{\star}$ P. K. Diwakar and A. Hassanein
}

Correction for 'Characterization of laser ablation sample introduction plasma plumes in fs-LA-ICP-MS' by N. L. LaHaye et al., J. Anal. At. Spectrom., 2014, DOI: 10.1039/c4ja00200h.

Following eqn (2) it is incorrectly stated that ' $Z$ is the atomic number of the element' but this should be ' $Z$ is the partition function'. The Royal Society of Chemistry apologises for these errors and any consequent inconvenience to authors and readers. 